Of the total financial return from a wattle plantation in Natal, 56 per cent was derived from the sale of bark, 33 per cent from mine props, and 11 per cent from fuel. Natal, which is now one of the main centres of the wattle bark industry, offers a favourable climate for the cultivation of the black wattle, and at present cheap native labour is available for stripping and handling the bark. "According to the secretary of the Wattle and Timber Growers' Association, the present value of the South African wattle industry may be assessed, at a conservative estimate, at $£ 2,000,000$ a year, of which more than half is money brought into the country by the export of bark and extract." It is therefore not surprising that the Forest Department of the South African Government has organised a comprehensive scheme of sylvicultural research, dealing with growth measurements, standard yields, optimum age, incidence and extent of insect attacks, fertilisers, etc. Encouraging results have also attended the experimental cultiva- tion of A. mollissima and other species in Kenya Colony, Tanganyika, and India.

Chestnut extract is produced mainly from the wood, which when air-dried contains about 8-13 per cent of tannin. The chief producing countries are France, Italy, and the United States, and of the overseas countries of the British Empire only India and Burma offer possibilities for the exploitation of species of chestnut as sources of tannin. Researches carried out at the Forest Research Institute at Dehra Dun have indicated that trees from Burma yield a richer extract than the European trees, but it is doubtful whether the product could be marketed economically under the prevailing conditions.

In these remarks it has been possible to comment only upon a few of the many facts, figures, and investigations finding mention in an unusually interesting publication, which, we are informed, has already been published on the continent in the form of a German translation.

\title{
Research in Freshwater Biology and the Functions of a Freshwater Biological Station.
}

\section{By Prof. F. E. Fritsch.}

$\mathrm{F}^{2}$ RESHWATERS are put to many different uses. Primarily they are the source of domestic water-supplies, including the huge amount of water required for sanitary purposes. Fresh water is, further, employed in enormous quantities in most, if not all, manufacturing processes. Flowing water is increasingly used as a source of power, while many British waterways serve as a means of communication. An appreciable section of the population, moreover, find relaxation in freshwater fisheries, while many a lake or stream is the centre-point of a beauty spot.

At the same time streams (and sometimes other linds of waters) serve as the natural recipients of sewage, only too often incompletely purified, and of the waste effluentis from a great diversity of chemical works and factories. During the course of the nineteenth century the quick growth of urban populations and the rapid industrial development combined, as a consequence, to bring about a very serious state of pollution in many British rivers, with the result that fish-life was appreciably diminished, and certain kinds, like salmon and trout, disappeared altogether from the more strongly polluted waters. This led to the appointment of a series of Pivers Pollution Commissions, which sat from 1865 onwards, and the reports of which are classical pieces of work which gave to Great Britain a lead of thirty to forty years in water-investigation. Yet, since then, and particularly on the experimental side, we have been far outdistanced by other countries. In the present century, and especially since the War, however, public opinion has again become alive to the evils attendant upon wholesale water-pollution, and various committees have been set up to deal with the matter. Among these, special mention may be made of the Standing Committee on Rivers Pollution appointed by the Ministry of Agriculture and Fisheries in 1921, and the Water Pollution Research Board established in 1927.

The three non-technical reports published by the former Committee (1924-26) contain abundant references both to the lack of scientific knowledge on the organic life of stream and lake and to the need for its acquisition. In the second report (p. 19) it is emphasised as essential that "those responsible for the work of river regeneration should have at their disposal the fullest scientific information bearing on the subject", whilst on p. 24 the same report continues: "At bottom, the problem is doubtless a question of the balance between all the different forms of animal and vegetable life under the particular environmental conditions which prevail ", and (p. 12 of the third report) "it is upon the abundance and well-being of these small organisms that the fish-life ultimately depends".

It is, however, not merely in relation to pollution and fisheries that a complete knowledge of the biology of British freshwaters must be of paramount economic importance. It is no less essential from the point of view of domestic water supplies, while ignorance on this subject is no doubt often the unrecognised cause of difficulties or deficiencies in various manufacturing processes in which water plays a considerable rôle. Moreover, a biological treatment of the effluents may well become a practicable matter in certain cases. Nor can it be doubted that fish-breeding would profit from a more adequate knowledge of aquatic biology.

What, then, is the state of our knowledge as regards the biology of freshwaters in general and of our own in particular? Professional biologists and amateur naturalists have done much to acquaint us with the multifarious aquatic fauna and flora, but there are immense gaps in our knowledge. Collecting has been carried out mostly during the warmer period of the year, and few data are available as regards 
the fauna and flora during the winter months. Again, the organisms that thrive in the deeper water of rivers and lakes, and especially those that inhabit the stream-bed or the lake-bottom, are, as a result of their relative inaccessibility, very imperfectly known. Our ignorance in this respect is much greater on the botanical than on the zoological side. A recently published account of the attached algal communities of certain British streams includes the description of a new genus and several new species, and analogous investigations in other quarters would probably afford a like result. We are thus at the present time quite inadequately familiar with the organisms that occur in freshwaters, yet whose individual presence or absence may be an index of the purity of the water and the cause of important biological changes. Our knowledge of the life-histories, except in a very few forms, is incomplete, and in only too many cases nil.

Moreover, although at present only clearly demonstrated for small ponds and for the macroplankton communities of larger waters, it is apparent that the microscopic fauna and flora exhibit a very definite annual periodicity and one, too, that varies appreciably in successive years. Such variations in the amount and time of occurrence of the diverse organisms are certainly an expression of corresponding variations in the environment, and by correlating the two, a number of important hints as to the causes underlying the appearance and extent of development of the various denizens of a piece of water are to be obtained.

Conclusions of this kind, however, require to be supported by experiment and by a far more comprehensive chemical and physical analysis of the environment than has hitherto been undertaken. Such work would lead to results of fundamental value, not only from the purely academic point of view, but also because it would provide means of controlling to some extent the nature and degree of development of the organic life in freshwaters.

Again, we possess at present but very fragmentary ideas as to the interrelationships of the diverse animal and plant communities in lake and stream. Although data may be available as to the direct food of certain fish, the nature of the nutriment upon which their prey in its turn relies for sustenance is almost always unknown. Birge and Juday, working on the lakes of Wisconsin, have shown the great importance of the nannoplankton which furnishes a large proportion of the available organic food. Of the nature and extent of the nannoplankton in other waters, however, practically nothing is known. Nor are the interrelationships of the organic communities of freshwaters merely a question of food-relations.

The diverse problems just indicated are not by any means the only ones awaiting solution in the realm of aquatic biology, but have been selected because they are perhaps the most obvious. They are of a similar nature in many kinds of water, and a long stride will have been taken towards their solution by the selection of a typical area of freshwater for intensive investigation over a period of years. For this purpose a properly equipped laboratory, with a permanent staff of scientific workers, needs to be established in the immediate vicinity of one or more suitable water-surfaces. The problems are not such as can be solved by occasional visits followed by work in a university laboratory, but in practically all cases require daily observations and records made on the spot. Even a water sample does not remain the same if carried some distance before analysis.

The staff of such a laboratory would make it their business, not only to become acquainted with the fauna and flora all the year round, but also would undertake regular chemical and physical investigation of the water in order to correlate changes in the one with changes in the other. Plentiful experimental work would be necessary in order to substantiate the conclusions thus arrived at. Moreover, a detailed study of the life-history of many of the organisms present would have to be undertaken, since their whereabouts and state of existence during the absent' period would in many cases, no doubt, prove to have a direct bearing on their time of maximum abundance. An important function of such a station would further be to initiate new methods of limnological investigation and to test the efficacy of those in current use.

Freshwater biological laboratories of this kind have long been in existence on the continent, among the more important being those of Plön in Germany, Lunz in Austria, and Aneboda in Sweden, all supported by public funds and growing in importance vear by year. While the work at such stations should primarily be of the nature of fundamental pure research, it is highly desirable that those concerned with applied problems should already, at an early stage, occupy working places in the laboratory. While they may obtain considerable help from the permanent scientific staff, the latter would profit greatly from contact with the economic problems that have to be solved.

It is not considered necessary to stress the scientific importance of such an institution, which was made sufficiently clear in the widely attended joint discussion between sections $\mathrm{D}$ and $\mathrm{K}$ at the Glasgow (1928) meeting of the British Association on "The Biological Investigation of British Freshwaters". An additional point to be made, however, is that a station of this kind would soon furnish a quota of limnological workers who could be drawn upon for the solution of applied problems, whilst it would stimulate work in other parts of the Empire and provide instruction in modes of attack.

It is with the prime purpose of securing the establishment of such a laboratory that the Freshwater Biological Association of the British Empire (inaugurated at a meeting held in the rooms of the Linnean Society of London in June of last year) has been founded. In order to arouse public interest and to initiate the raising of the necessary funds, the Council of the Association has invited all interested parties to a meeting to be held at 2.30 P.M. on Feb. 21 next, at Fishmongers' Hall, by kind permission of the Court of the Fishmongers' Company. The chair will be taken by the Right Hon. Lord Rothschild, president of the Association.

No. 3146, VoL. 125] 